\title{
Zinc Oxide Nanowires Synthesized using a Hot Tube Thermal Evaporation under Intermediate Heating Period
}

\author{
Samsudi Sakrani ${ }^{1 *}$, Peshawa Omer $\operatorname{Amin}^{2}$ and Syahida Suhaimi ${ }^{1}$ \\ ${ }^{1}$ Ibnu Sina Institute for Fundamental Science Studies, University Technology Malaysia, 81310 Johor, Malaysia, \\ ${ }^{2}$ Department of Physics, School of Science Education, University of Sulaimani, Sulaimani, Iraq \\ Received 26 January 2013, Revised 10 May 2013, Accepted 21 May 2013, Available online 1 June 2013
}

\begin{abstract}
Zinc oxide nanowires have been synthesized using a hot tube vacuum evaporation method. Essentially, ZnO powder and silicon substrate were placed in upper and lower streams of a horizontal quartz tube, respectively and heated via a furnace up to $960 \mathrm{C}$ for about 1 hour. During the heating process, evaporated $\mathrm{ZnO}$ vapour was transported to lower stream and deposited onto the substrate containing Au catalyst at constant pressure of 1 torr. The substrate tilt angles were chosen for $0^{\circ}$ and $30^{\circ}$ and argon flow rates between 1.1-5.0 sccm. Observation on FESEM/EDX and field emission results revealed the optimal growth of $\mathrm{ZnO}$ nanowires which occurred at an angle $30^{\circ}$ and flow rate of $5 \mathrm{sccm}$. Parameters such as atom\% of $\mathrm{Zn}$ and $\mathrm{O}$ and aspect ratio were measured and analysed.
\end{abstract}

| Hot-tube thermal evaporation | ZnO Nanowires | Vapour-liquid-solid mechanism |

( 2013 Ibnu Sina Institute. All rights reserved. http://dx.doi.org/10.11113/mjfas.v9n4.109

\section{INTRODUCTION}

$\mathrm{ZnO}$ is a semiconductor which possesses the characteristics of wide band gap of $3.37 \mathrm{eV}$, large exciton binding energy of $60 \mathrm{meV}$ at room temperature, as well as high mechanical and thermal stabilities. In recent years, there has been increasing interest in $\mathrm{ZnO}$ nanostructures such as nanowires, nanorods, nanobelts and nanotubes due to their unique physical properties and potential applications in electronics, optics, photonics and sensing devices [1]. Various synthesizing methods of $\mathrm{ZnO}$ nanostructures were reported elsewhere [2-7], including thermal evaporation, CVDs and electro-deposition. The catalysts used in the thermal evaporation of $\mathrm{ZnO}$ nanostructure consisted of $\mathrm{Au}, \mathrm{Cu}, \mathrm{Sn}$ or other additives such as $\mathrm{Ga}$ and $\mathrm{NiO}$ [8-12] in order to assist and control the growth process. Additionally, a silicon substrate has an advantage over other choices due to its compatibility in the semiconductor integrated processing techniques. However, problem may arise in growing well-aligned $\mathrm{ZnO}$ nanowires on a $\mathrm{Si}$ substrate due to a rather large residual strain $[13,14]$, developed when the large differences in the lattice constants and the thermal expansion characteristics between the $\mathrm{ZnO}$ nanowires and the $\mathrm{Si}$ occurs. This study is aimed at establishing the intermediate growth conditions for $\mathrm{ZnO}$ nanowire arrays on $\mathrm{Si}$ (100) substrates coated with $\mathrm{Au}$ catalyst, with a highlight on the substrate tilt angle and argon flow rate.

\section{EXPERIMENTAL}

Randomly oriented, catalytic growth of $\mathrm{ZnO}$ nanowire was fabricated by means of a hot tube thermal evaporation process in a horizontal-tube furnace reactor. Pure $\mathrm{ZnO}$ powders (purity 99.99\%) were placed in an alumina boat and heated to $960{ }^{\circ} \mathrm{C}$. The $\mathrm{ZnO}$ vapour was carried downstream by a 1.1 to $5.0 \mathrm{sccm}$ Ar flow and condensed along the colder regions of the furnace tube where the Au-coated substrates were placed. Typical substrate tilt angles were set at $0^{\circ}$ and $30^{\circ}$, with their temperatures expected to fall below $1000{ }^{\circ} \mathrm{C}$. The $\mathrm{Ar}$ pressure was set to 10 mbar during growth and 0.1 bar during the temperature ramps, to provide pressure-based growth interruptions and avoid non-steady-state effects [15]. It is believed that the nanowires are generated directly from the vapour phase in the absence of a metal catalyst, and this process is often called vapour-solid (VS) growth. To generate the vapour phases of the source materials, vacuum conditions are sometimes needed. This is because some materials may not sublimate in the normal atmosphere. An effective way to generate the vapour source materials in a normal atmosphere is to add additional materials to react with the source materials. For example, $\mathrm{ZnO}$ powder does not sublimate in a normal atmosphere at $1000{ }^{\circ} \mathrm{C}$. By adding carbon powder to react with the $\mathrm{ZnO}$ source, $\mathrm{Zn}$ or $\mathrm{Zn}$ suboxide vapor phases can be easily generated at $1000{ }^{\circ} \mathrm{C}$. Various forms of $\mathrm{ZnO}$ nanostructures grow in the lowtemperature zone. In this case, vacuum conditions, carrying 
gases and catalysts are all unnecessary. Fig. 1 shows the experimental set up for synthesizing $\mathrm{ZnO}$ nanowires.

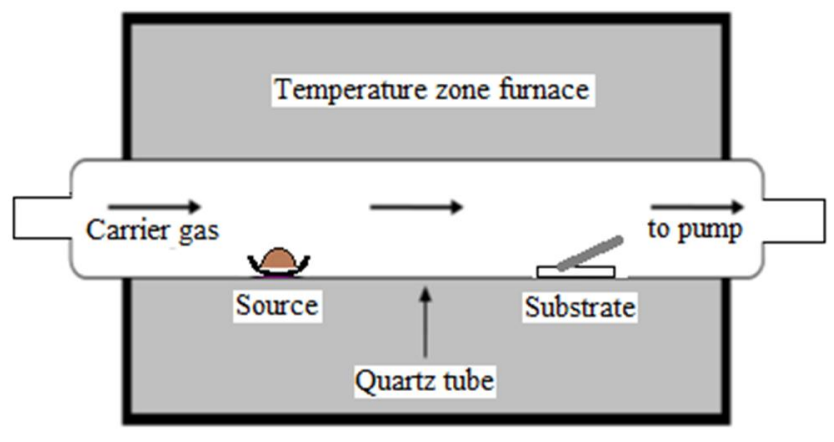

Fig. 1 Schematic of experimental setup

In the above experiment, $\mathrm{Zn}$ or $\mathrm{Zn}$ suboxide play a crucial role for the nucleation of $\mathrm{ZnO}$ nanostructures. This is because that at a high temperature condition $\left(\mathrm{T}>1100{ }^{\circ} \mathrm{C}\right)$, carbon reduced $\mathrm{ZnO}$ into $\mathrm{Zn}$ or $\mathrm{Zn}$ suboxides by the following reactions [15]:

$2 \mathrm{ZnO}+\mathrm{C} \rightarrow \mathrm{Zn}+\mathrm{CO}_{2}$

$\mathrm{ZnO}+\mathrm{CO} \rightarrow \mathrm{Zn}+\mathrm{CO}_{2}$

$\mathrm{ZnO}+(1-\mathrm{x}) \mathrm{CO} \rightarrow \mathrm{ZnO}_{\mathrm{x}}+(1-\mathrm{x}) \mathrm{CO}_{2}$

In case of the sealed quartz tube the carbon powder might directly react with $\mathrm{ZnO}$, whilst for the case of the open-end quartz tube carbon first react with oxygen to form $\mathrm{CO}$. $\mathrm{Zn}$ and $\mathrm{Zn}$ suboxides have low melting temperatures (approximately $419^{\circ} \mathrm{C}$ for both $\mathrm{Zn}$ and $\mathrm{ZnO}_{\mathrm{x}}$, where $\mathrm{x}<1$ ) compared to that of $\mathrm{ZnO}\left(1975{ }^{\circ} \mathrm{C}\right)$ and should be in vapour phases at $1100{ }^{\circ} \mathrm{C}$. At the low temperature site, $\mathrm{Zn}$ vapour generated by reactions (2) and (3) will condense on the inner wall of the quartz tube forming liquid droplets, which are ideal catalysts for $\mathrm{ZnO}$ nanowire growth through the VLS mechanism. Carrying gases are not necessary for the formation of $\mathrm{ZnO}$ nanostructures. Temperature is the critical experimental parameter for the formation of different morphologies of $\mathrm{ZnO}$ nanostructures.

The addition of carbon during the reaction causes $\mathrm{Zn}$ vapour or droplets to partially oxidized and forming suboxides, which generally have low melting temperatures. This suboxides $\left(\mathrm{ZnO}_{\mathrm{x}}\right)$ is formed because the amount of oxygen contributing to the reaction in the open-end quartz tube is limited. Such a condition is reasonable since $\mathrm{Zn}$ droplets coexist with $\mathrm{ZnO}$ nanowire products in the early stage of the nanowire formation. Either $\mathrm{Zn}$ droplets or vaporized $\mathrm{Zn}$ suboxide droplets could be the nuclei for $\mathrm{ZnO}$ nanowires. Similar to the oxide-assisted growth mechanism $\mathrm{Zn}$ suboxides are more reactive than $\mathrm{ZnO}$ and may largely enhance the deposition of $\mathrm{Zn}$ oxides at the tips of $\mathrm{ZnO}$ nanowires during growth. Due to further oxidation of $\mathrm{Zn}$ or $\mathrm{Zn}$ suboxides, the concentration of oxygen in the droplets/tips increases, and thus $\mathrm{ZnO}$ deposits on the interface between the droplets and substrate, resulting in the growth $\mathrm{ZnO}$ nanowires.
The grown $\mathrm{ZnO}$ nanowires were characterized by a field emission scanning electron microscope (FESEM, JEOL JSM-6701F, Japan), combined with EDX for morphological and compositional analysis. Also, photoluminescence (LS55 Luminescence Spectrometer from Perkin Elmer) measurements performed using the 325 $\mathrm{nm}$ line of a He-Cd laser as the excitation source with a 350 $\mathrm{nm}$ filter to determine the field emission properties.

\section{RESULTS \& DISCUSSION}

\subsection{Structural Properties}

\subsection{Influence of Substrate Tilt Angle}

In this study, substrate was placed at a fixed distance of $18 \mathrm{~cm}$ from the source and tilted $0^{\circ}$ and $30^{\circ}$ toward the horizontal. This make it different from the previous practice of placing substrate either above the source material [16] or next to the source material in the direction of carrier gas that makes zero degree $\left(0^{\circ}\right)$ with horizontal axis $[17,18]$. The effect of tilt angle on the structural properties of $\mathrm{ZnO}$ nanowires is discussed. Figs. 2 and 3 show the FESEM images of $\mathrm{ZnO}$ nanowires for the tilt angles of $0^{\circ}$ and $30^{\circ}$, respectively. Generally, the nanowires appear to be randomly oriented with the aspect ratio of the former sample smaller (5.5) that that of latter one (7.7). However, in terms of density samples with tilt $0^{\circ}$ has slightly higher value. Figs. 4 and 5 demonstrate the EDX spectra for both samples which comprised of a strong dominant peak of $\mathrm{Si}$ (substrate) and small peaks $\mathrm{Zn}$ and $\mathrm{O}$ ( $\mathrm{ZnO}$ nanowires), as well as $\mathrm{Au}$ (catalyst).

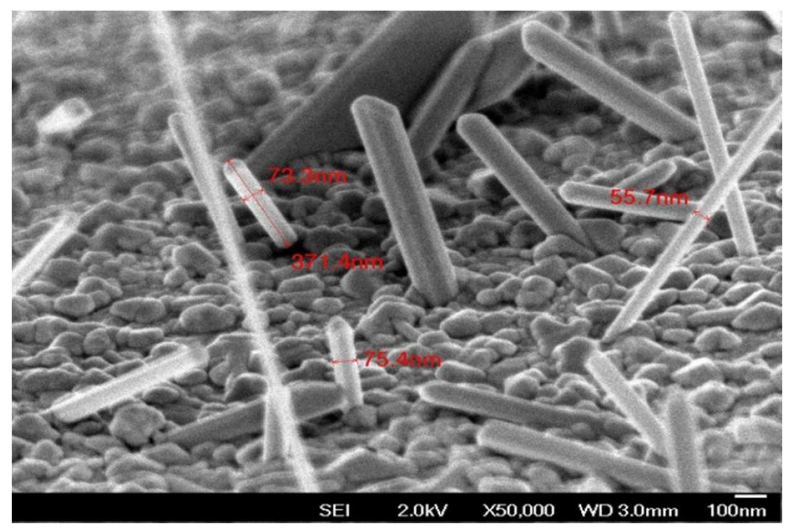

Fig. 2 FESEM images at angle $0^{\circ}$

Further analysis reveals the atomic percentage or amount of precursors (source atom) of the samples. Apparently, the atomic\% of both $\mathrm{Zn}$ and $\mathrm{O}$ appears to be slightly changed, with the trend of reducing $\mathrm{Zn}$ and rich $\mathrm{O}$ content possibly due to more increased reaction at angle $30^{\circ}$. It may suggest that, chemical oxidation described in equations (2) and (3) is more likely to occur at this stage, thus producing more $\mathrm{ZnO}$ nanowires. is more actively Refer 
to Table 1 . Therefore, angle $30^{\circ}$ was fixed for the preceding experiment.

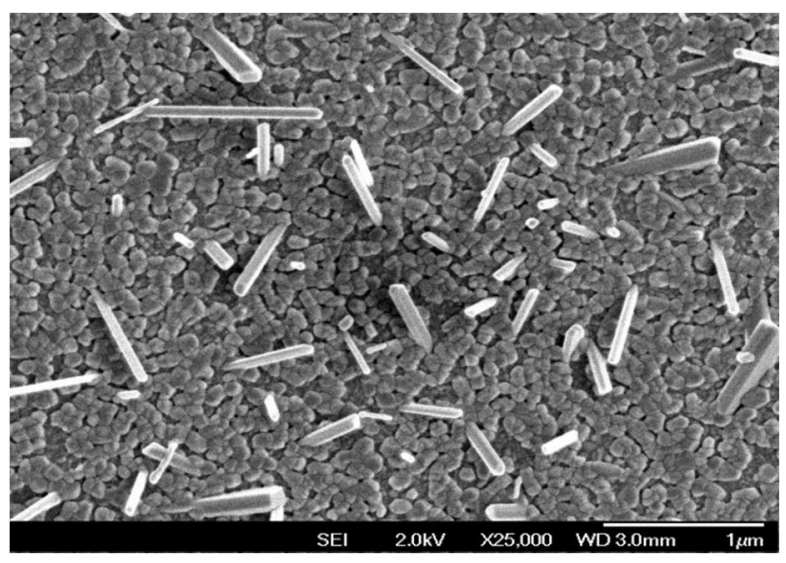

Fig. 3 FESEM images at angle $30^{\circ}$.

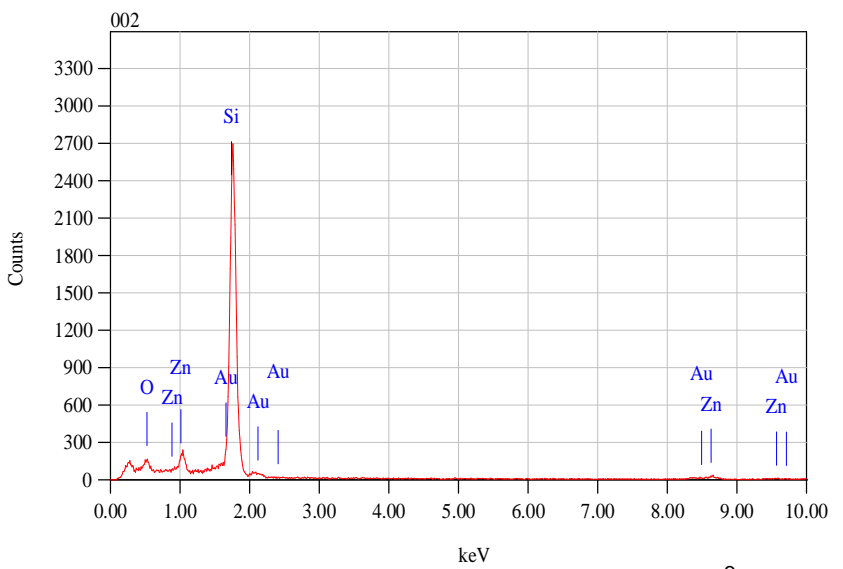

Fig. 4 EDX spectra at substrate tilt angle $0^{\circ}$.

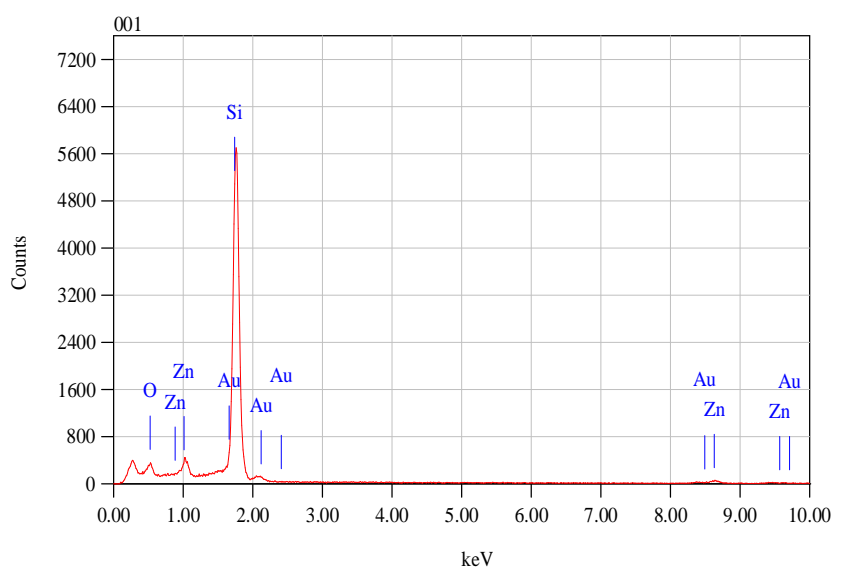

Fig. 5 EDX spectra at substrate tilt angle $30^{\circ}$

Table 1 Effect of substrate tilt angle

\begin{tabular}{|c|c|c|c|}
\hline $\begin{array}{c}\text { Substrate } \\
\text { angle, } \theta\left({ }^{\circ}\right)\end{array}$ & Zn (Atom\%) & $\mathrm{O}$ (Atom\%) & $\begin{array}{c}\text { Aspect } \\
\text { Ratio }\end{array}$ \\
\hline 0 & 7.47 & 11.98 & 5.5 \\
\hline 30 & 7.37 & 12.82 & 7.7 \\
\hline
\end{tabular}

\subsection{Influence of Flow Rate}

The influence of argon flow rate is considered to be very significant in determining the nature of $\mathrm{ZnO}$ nanowires [19]. Essentially, three different concentrations; $1.1,3.0$ and $5.0 \mathrm{sccm}$ were fixed, and the corresponding samples were analysed for each category. Other setting parameters were; tilt angle $30^{\circ}$, substrate-source distance 18 $\mathrm{cm}$, furnace temperature $960{ }^{\circ} \mathrm{C}$ and heating duration 60 mins. Figs. 6, 7 and 8 show FESEM images which appear to be different in densities, sizes, and stability of the nanowires. This trend is in a good agreement with Meng et al. [19]. At flow rate $1.1 \mathrm{sccm}$, the growth is limited to about 4 nanowires per area and average size of $83 \mathrm{~nm}$ (Fig. 6). Similar unstable nanowires are also observed in Fig. 7, but with increased density of 16 nanowires per area and size of $86 \mathrm{~nm}$. A further increase of flow rate to $5 \mathrm{sccm}$ results in more stable nanowires (Fig. 8), indicated by smooth background and high aspect ratio of 10.5. Analysis from EDX spectra are shown in Figs. 9, 10 and 11 which explain the possible growth mechanism of $\mathrm{ZnO}$ nanowires. Table 2 lists down the changes in atom\% of the species involved, excluding the background contamination from Pt due to pre-cleaning procedures.

Table 2 Effect of argon gas flow rate

\begin{tabular}{|c|c|c|c|}
\hline $\begin{array}{c}\text { Ar Flow Rate } \\
\text { (sccm) }\end{array}$ & $\begin{array}{c}\mathrm{Zn} \\
\text { (Atom\%) }\end{array}$ & $\begin{array}{c}\mathrm{O} \\
\text { (Atom\%) }\end{array}$ & $\begin{array}{c}\text { Aspect } \\
\text { Ratio }\end{array}$ \\
\hline 1.1 & 0.29 & 1.82 & 8.6 \\
\hline 3.0 & 0.82 & 1.23 & 4.1 \\
\hline 5.0 & 1.67 & 6.05 & 10.5 \\
\hline
\end{tabular}

The above results indicate a significant influence of argon flow rate on the both atom\% and aspect ratio. An increase of atom\% is expected by the increased amount of precursor $(\mathrm{ZnO}$ vapour) transported onto the inclined substrate, thus allowing more oxidations at the tilted substrate to produce $\mathrm{ZnO}$ nanowires with improved densities and aspect ratios. Except for $3.0 \mathrm{sccm}$ the discrepancy might be caused by the limited number of samples analysed at this stage. This result suggests a flow rate of $5.0 \mathrm{sccm}$ and deposition time greater than 1 hour for producing better aspect ratio of $\mathrm{ZnO}$ nanowires.

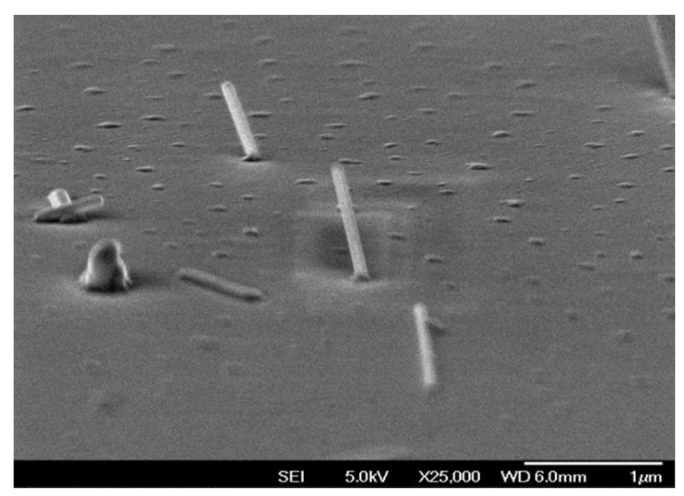

Fig. 6 FESEM images at flow rate of $1.1 \mathrm{sccm}$. 


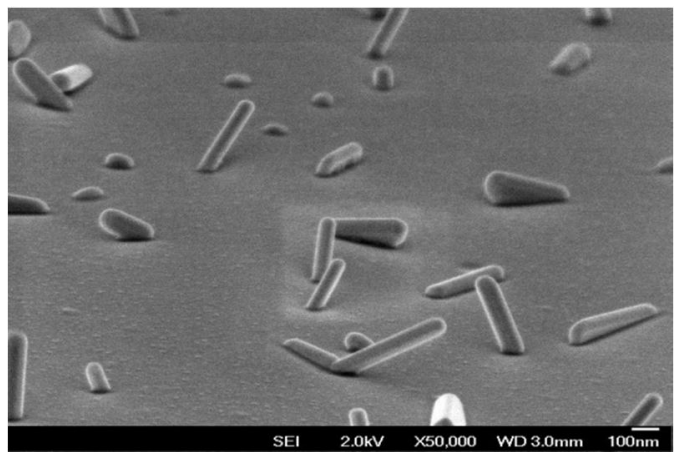

Fig. 7 FESEM images at flow rate of $3 \mathrm{sccm}$.

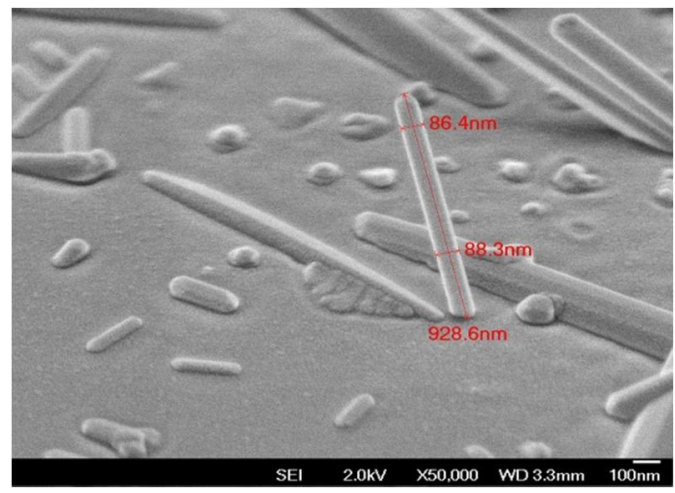

Fig. 8 FESEM images at flow rate of $5 \mathrm{sccm}$

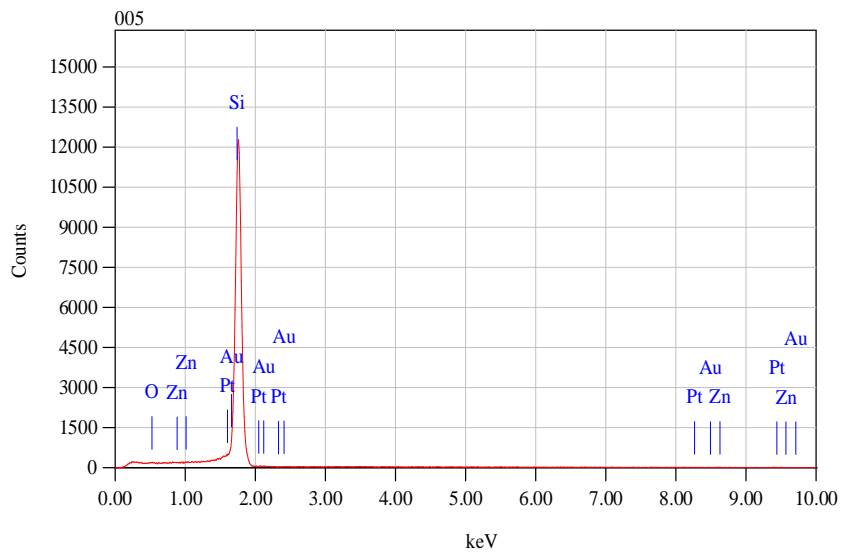

Fig. 9 EDX spectra at flow rate $3 \mathrm{sccm}$

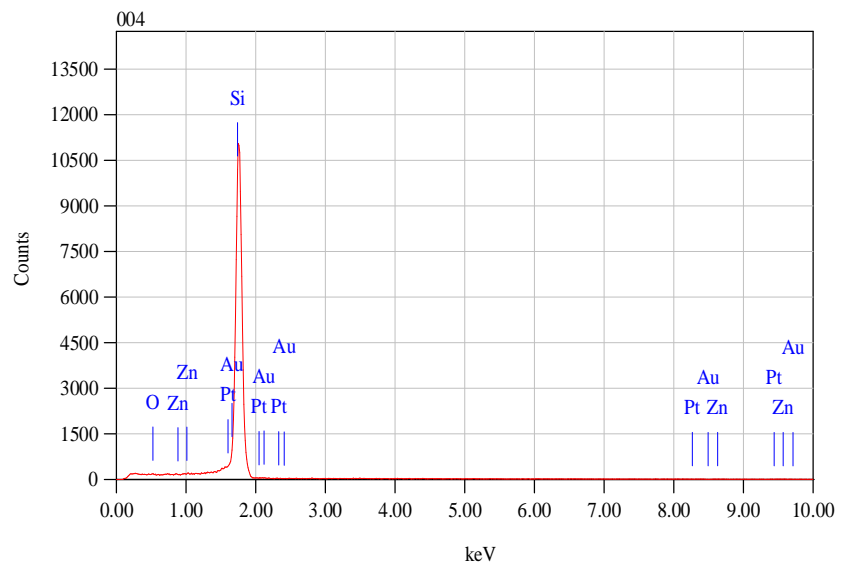

Figure $10 \mathrm{EDX}$ spectra at flow rate $3 \mathrm{sccm}$
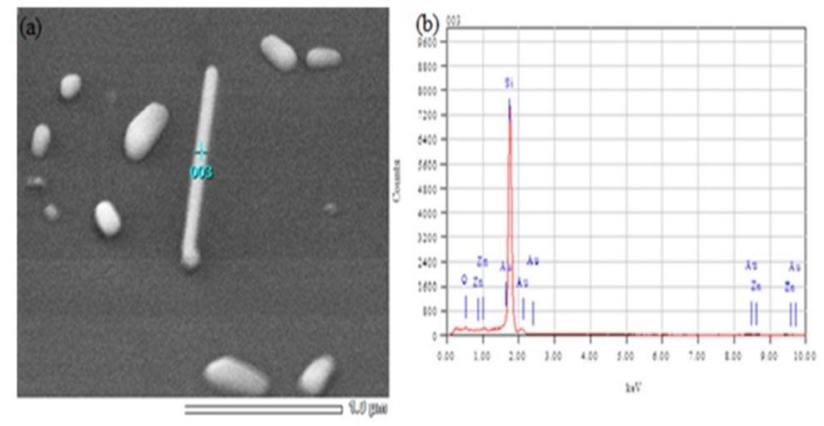

Fig. 11 EDX spectra at flow rate $5 \mathrm{sccm}$, showing the measured position of $\mathrm{ZnO}$ nanowire

\subsection{Field Emission Properties}

\subsubsection{Effect of Tilt Angle}

The room temperature emission spectrum of $\mathrm{ZnO}$ nanowires shown in Fig.12 was obtained in the UV region and visible region (longer wave lengths of more than 400 $\mathrm{nm}$ for two samples). Samples A and B were placed inside the quartz tube at angles $0^{\circ}$ and $30^{\circ}$, respectively. From the PL measurements sample A exhibits a broad emission from UV region to visible region and show two peaks at 375 and $430 \mathrm{~nm}$ (curve a). The peak emission at $375 \mathrm{~nm}\left(E_{g}=3.3\right.$ $\mathrm{eV}$ ) corresponds to the near band-band edge emission of $\mathrm{ZnO}[21]$ and the other peak at $430 \mathrm{~nm}\left(E_{g}=2.88 \mathrm{eV}\right)$ as evident for radiative recombination processes connected to defect or impurity present in the nanowires. In contrast, sample B exhibits a broad emission (blue emission) band extending approximately from 340 to $540 \mathrm{~nm}$ with a single peak at $440 \mathrm{~nm}$ (curve b). The peak represents a broad emission band of the nanowires in the visible spectral range $E_{g}=2.81 \mathrm{eV}$, and its origin is somewhat controversial. Nevertheless, there is increasing consensus that it arises from radiative recombination processes related to defects/ impurity complexes [20].

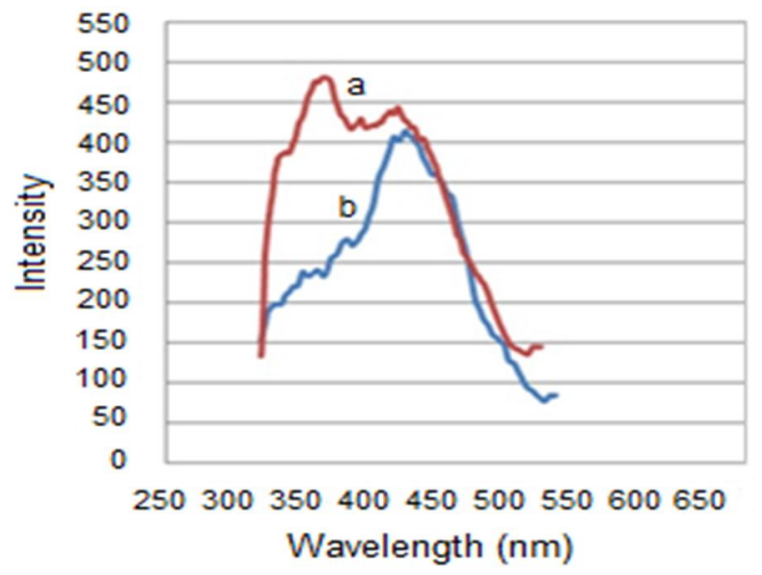

Fig. 12 Emission spectra at different substrate tilt angles: a) $0^{\circ}$ and b) $30^{\circ}$ 


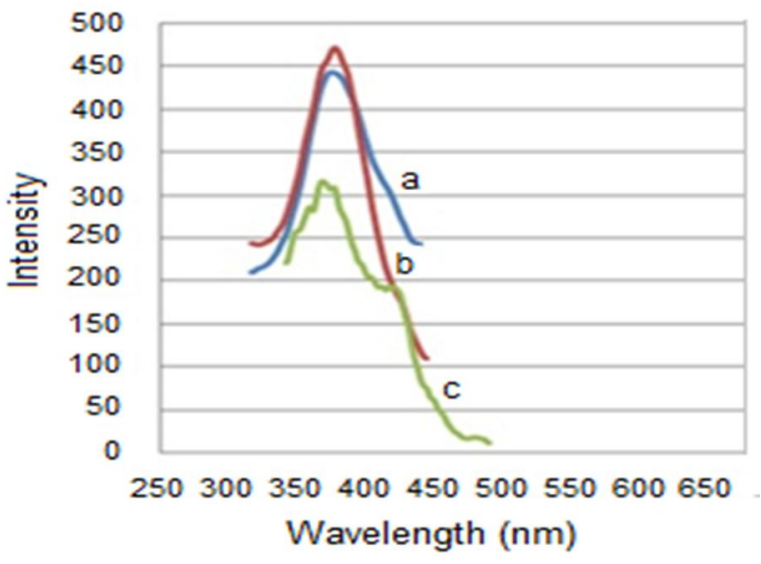

Fig. 13 Emission spectra at flow rates: (a) $1.1 \mathrm{sccm}$, (b) 3 sccm and (c) $5 \mathrm{sccm}$

\subsubsection{Effect of Flow Rate}

Field emission spectrums of the room temperature PL measurements were carried out to examine the effect of the flow rate on optical properties of $\mathrm{ZnO}$ nanowires and the results are shown in Fig.13. Three samples were synthesized at three different flow rates $1.1,3$, and $5 \mathrm{sccm}$ and denoted a, b, and c, respectively. All three samples have the same ultraviolet emission peak at $374 \mathrm{~nm}\left(E_{g}=\right.$ $3.31 \mathrm{eV}$ ) but with different intensities. The $374 \mathrm{~nm}$ emission is approximately corresponding to the recombination of free excitons between the conduction band and the valence band; this is called the near band-edge emission [20]. The band at the longer wave length could be attributed to the radial recombination of photon-generated holes with electrons belonging to the singly ionized oxygen vacancy in $\mathrm{ZnO}$. The strong UV emission in the PL spectra indicates that $\mathrm{t}$ have good crystalline quality with disappearances of green emission [17]. Fig.14 shows the field emission spectra of an additional sample synthesized at $5 \mathrm{sccm}$ flow rate and $90 \mathrm{~min}$. growth time. The curve shows an ultraviolet emission peak shifting from $350 \mathrm{~nm}$ $\left(E_{g}=3.54 \mathrm{eV}\right)$ to $380 \mathrm{~nm}$, which may attribute to the presence of defect or impurity in the nanowires.

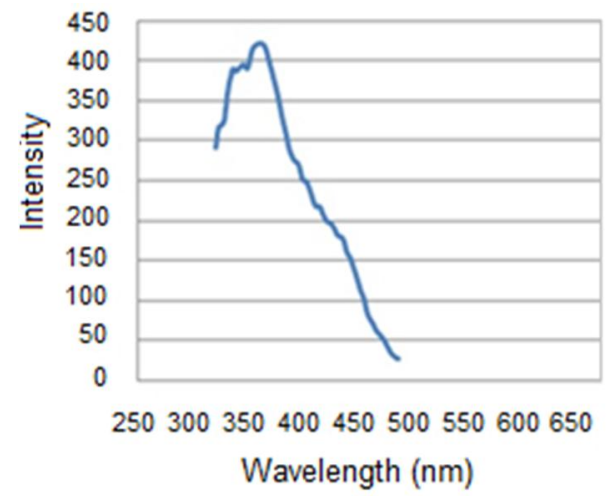

Fig. 14 Emission spectra at $5 \mathrm{sccm}$ and longer growth time of 90 minutes

\section{CONCLUSION}

$\mathrm{ZnO}$ nanowires have been successfully grown on $\mathrm{Si}$ (100) substrate using a hot tube thermal evaporation under the optimal setting parameters of substrate tilt angle $30^{\circ}$ and argon flow rate of $5 \mathrm{sccm}$. These resulted in $\mathrm{ZnO}$ nanowires with improved densities, sizes and most important was higher aspect ratio. Emission properties of nanowires: Peak at around $380 \mathrm{~nm}$ over the visible region, but could slightly shifted due to different processes and contaminations

\section{ACKNOWLEDGEMENT}

We greatly appreciate the support from Universiti Teknologi Malaysia through RMCổ Research University Grant (Tier 1: J130000.7126.01H38). The authors also thank all those involved for their dedication and hard work to ensure the research is successful.

\section{REFERENCES}

[1] Y. Xia, P. Yang, Y. Sun, Y. Wu, B. Mayers, B. Gates, Y. Yin, F. Kim and H. Yan, Adv. Mater 15 (2003) 353-389.

[2] W.I. Park, D.H. Kim, S.W. Jung and G.C. Yi, Appl. Phys. Lett., 80 (2002) 4232-4234.

[3] B.P. Zhang, N.T. Binh, Y. Segawa, K. Wakatsuki and N. Usami, Appl. Phys. Lett., 83 (2003) 1635-1637.

[4] Y.C. Kong, D.P. Yu, B. Zhang, W. Fang and S.Q Feng, Appl. Phys. Lett., 78 (2001), 407-409.

[5] Y. Sun, G.M. Fuge and M.N.R. Ashfold, Chem. Phys. Lett., 396 (2004) 21-26.

[6] M.H. Huang, Y. Wu, H. Feick, N. Tran, E. Weber and P. Yang, Adv. Mater., 13 (2001) 113-116.

[7] C. Li, G. Fang, S. Xu, D.S. Zhao and X.Z. Zhao, Nanotechnology, 17 (2006) 5367-5372.

[8] H.J. Fan, B. Fuhrmann, R. Scholz, F. Syrowatka, A. Dadgar, A. Krost and M. Zacharias, J. Cryst. Growth, 287 (2006) 34-38.

[9] S.Y. Li, C.Y. Lee and T.Y. Tseng, J. Cryst. Growth, 247 (2003) 357-362.

[10] P.X. Gao, Y. Dinh and Z.L. Wang, Nano Lett., 9 (2004) 1315-1320.

[11] Y.K. Tseng, C.J. Huang, H.M. Cheng, I.N. Lin, K.S. Liu and I.C. Chen, Adv. Funct. Mater., 13 (2003) 811-814.

[12] S.C. Lyu, Y. Zhang, C.J. Lee, H. Ruh and H.J. Lee, Chem. Mater., 15 (2003) 3294-3299.

[13] Y. Zhang, H. Jia and D.Yu, J. Phys. D: Appl. Phys., 37 (2004) $413-$ 415.

[14] H.C. Hsu, C.S. Cheng, C.C. Chang, S. Yang, C.S. Chang and W.F. Hsieh, Nanotechnology, 16 (2005) 297-301.

[15] N. Wang, Y. Chai and R.O. Zhang, Mater. Sci. and Engineering, R60 (2008) 1-51.

[16] J. Yang,, D. Wang, L. Yang, Y. Zhang, G. Xing, J. Lang, H. Fan, M. Gao and Y. Wang, Journal of Alloys and Compounds, 86 (4) (2007) 433 ï 440.

[17] H. I. Abdulgafour, Z. Hassan, N. H. Al Hardan and F. K. Yam, Physica B, 405(2010) 4216-4218.

[18] J. H. Zeng, Y. L. Yu, Y. F. Wang,. and T. J. Lou, Acta material, 57 (2009) $1813 і ̈ 1820$.

[19] G. Meng, X. Fang, W. Dong, R. Tao, Y. Zhao, Z. Deng, S. Zhou, J. Shao and L. Li, Applied Surface Science, 256(2010) 6543 ï 6549.

[20] F. G"uell, J.O. Osso, A.R. Go"ni, A. Cornet and J.R. Morante, Superlattices and Microstructures, 45(2009) 271 ï 276. 